\title{
Treatment of Connective Tissue Disease-Related Intractable Disease with Biological Therapeutics
}

\section{Yoshio Ozaki \\ Shosaku Nomura}

First Department of Internal Medicine, Kansai Medical University, Hirakata, Japan

\begin{abstract}
The treatment of connective tissue disease (CTD) and CTD-related intractable diseases (CTD-IDs) currently depends on the use of steroid therapy. Approximately 20 years have passed since the approval of infliximab for rheumatoid arthritis in 2003. Since then, several biological therapeutics have been marketed and adapted for many CTDs and CTDIDs other than rheumatoid arthritis. Although conventional treatment for patients with these diseases is rarely used because of their poor prognosis, these cases may benefit from biological therapeutics. However, choosing biological therapeutics is difficult because they have different target molecules compared with conventional therapeutics. In this review, we address the current situation of biological therapeutics for CTD-IDs including Behcet's disease, psoriatic arthritis, ankylosing spondylitis, anti-neutrophil cytoplasmic antibodyrelated arthritis, and adult Still's disease, as well as the choice of biological therapeutics in clinical practice.
\end{abstract}

Keywords: connective tissue disease-related intractable disease, biological therapeutics, clinical practice, inflammatory cytokine

\section{Introduction}

Connective tissue disease (CTD) is a histopathological concept proposed by the American pathologist Paul Klemperer in $1942 .{ }^{1}$ It is used to describe acute or chronic diseases characterized by abnormalities including diffuse denaturation of the connective tissue (dermis, ligament, tendon, bone, cartilage), particularly extracellular components, such as collagen. Currently, six diseases including rheumatic fever, rheumatoid arthritis (RA), polyarteritis nodosa, systemic lupus erythematosus, systemic scleroderma and dermatomyositis are termed "classic CTDs". 2,3 CTD is a clinical diagnosis term for a single disease group with similar histopathological characteristic but not similar etiologies or genetics. ${ }^{4-6}$ In the current classification, several CTD-related intractable-disease (CTD-IDs) other than "classic CTDs" have been proposed including polymyositis, mixed CTD, Sjogren's syndrome, vasculitis syndrome, juvenile idiopathic arthritis, adult Still's disease (ASD), Behcet's disease (BD), and anti-phospholipid syndrome. ${ }^{7-9}$

Biological therapeutics are commonly used for the treatment of immunological disease and malignancy, because they are high effective compared with conventional treatments using small molecules. ${ }^{10}$ High polymer preparations, termed biological therapeutics, which block cytokines are used to treat CTD and rheumatic disease whereas molecules targets are required for the treatment of malignant tumor. ${ }^{10}$ First, rituximab was approved for the treatment of malignant lymphoma, resulting in
Correspondence: Shosaku Nomura First Department of Internal Medicine, Kansai Medical University, 2-3-I Shinmachi, Hirakata, Osaka, 573-1010, Japan

Tel +8I 728042754

Fax +8I 728042041

Email shosaku-n@mbp.ocn.ne.jp 
a breakthrough for blood disorders. ${ }^{11}$ Infliximab has been used to treat Crohn's disease and RA. ${ }^{12}$ Researchers predicted RA symptoms could be improved by blocking inflammatory cytokines such as tumor necrosis factor (TNF) $\alpha$, interleukin (IL)-6 and IL-1 $\beta$, because these cytokines were strongly related to the pathophysiology in RA. Then, biological therapeutics for BD, vasculitis, psoriatic arthritis (PsA), ankylosing spondylitis (AS), and systemic lupus erythematosus were developed and recommended by medical treatment guidelines for the treatment of each disease. ${ }^{13-16}$

In the field of medicine, biological therapeutics consist of proteins as well as insulin, immunoglobulin (Ig) preparations, and vaccines. However, in the field of CTD and CTD-ID, biological therapeutics describe drugs that inhibit the production or function of cytokines or kill specific lymphocyte populations. Biological therapeutics include monoclonal antibodies and protein fusion preparation (receptor molecules). In general, monoclonal antibodies destroy cytokine- or antibody- producing cells by the binding to a cell surface receptor or target antigen. Receptor molecules, also called decoy molecules, are fused to a receptor that binds to $\mathrm{IgG}$, which prevents the binding of the target (eg, cytokine) to its receptor. ${ }^{17}$ The first monoclonal antibody preparations were from mice, but their immunogenicity prevented their long-term use for clinical applications. To reduce immunogenicity, chimeric model antibodies, humanized antibodies, and human antibodies were developed. Human antibodies encoded by human antibody gene contain no mouse molecules (Figure 1). In this review, we discuss the current situation of biological therapeutics for CTD-IDs including BD, PsA, AS, anti-neutrophil cytoplasmic antibody (ANCA)-related arthritis, and ASD, as well as the choice of biological therapeutics for clinical practice.

\section{Behcet's Disease (BD)}

BD is characterized by inflammation of the skin, mucous membranes, and uvea. ${ }^{18}$ Uveitis, particularly posterior uveitis,

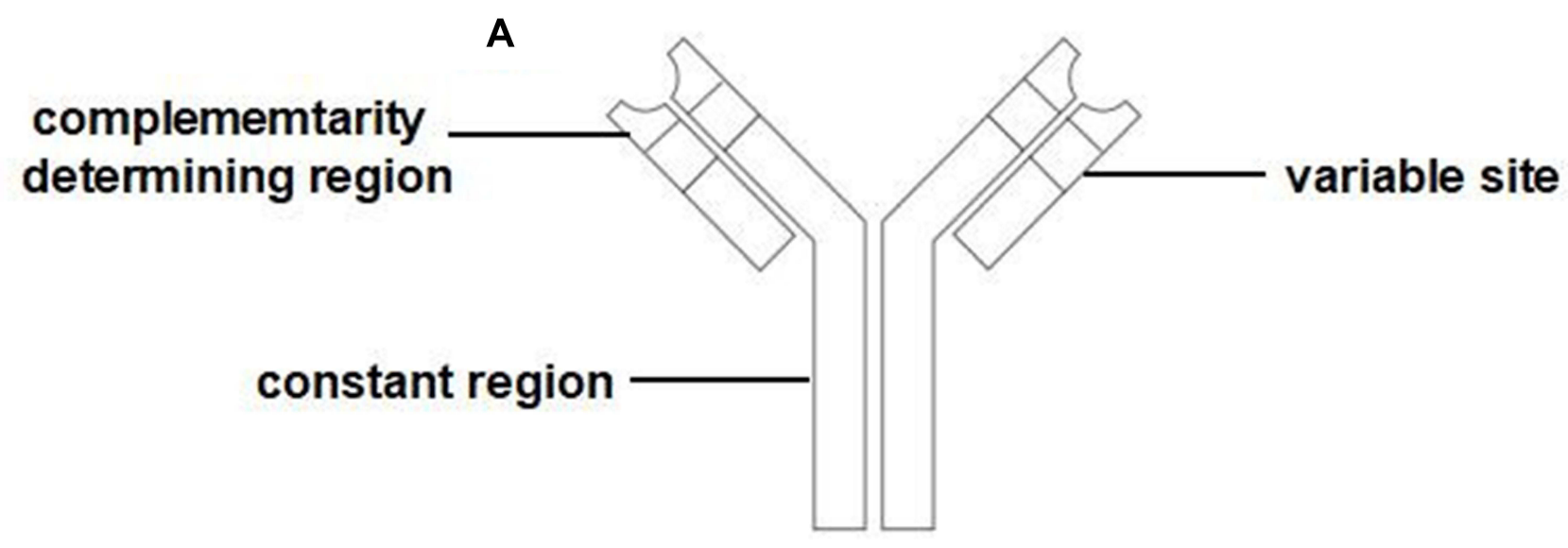

B

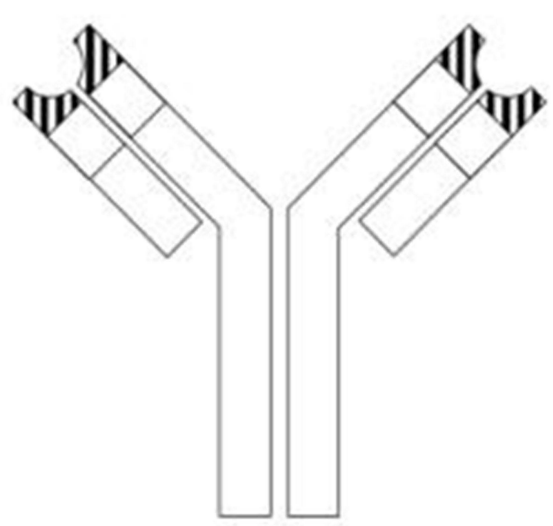

C

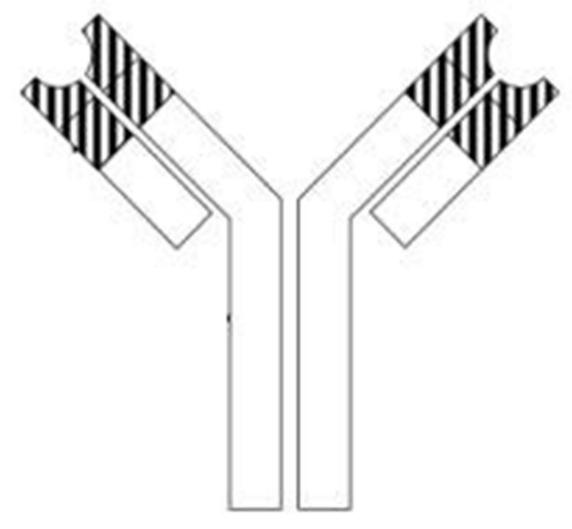

Figure I Three types of therapeutic immunoglobulins. (A) Human antibody; (B) Humanized antibody; (C) Chimeric model antibody Immunoglobulins consist of a complementarity determining region, variable site, and constant region. 
rarely causes altitude inflammation, which leads to blindness. ${ }^{8,18}$ Intestinal, vascular, and nervous BD often affect the disease prognosis. ${ }^{18}$ The pathogenesis of $\mathrm{BD}$ is related to TNF $\alpha .{ }^{19}$ T cells in BD patients respond to a small amount of staphylococcal exotoxins and produce cytokines. ${ }^{20}$ Two antiTNF $\alpha$ monoclonal antibodies (infliximab and adalimumab) have been adapted for BD treatment and infliximab has been approved for all types of BD. It is necessary to administer a combination therapy of methotrexate (MTX) and infliximab in RA patients because of the influence of anti-infliximab antibody production. However, this combination with MTX is unnecessary in BD patients. Furthermore, the addition of MTX does not provide benefit compared with infliximab treatment alone. However, when an immunosuppressant was used with adalimumab it was reported that "there might be the clearance drop of adalimumab by combination with MTX and uses it together and warns us". The frequency of uveitis is related to blindness. Therefore, for the treatment of BD uveitis, it is important to control eye inflammation. The whole-body dosage of glucocorticoids improves symptoms related to $\mathrm{BD}$, but the long-term control of BD is unknown. Oral immunized suppressants to treat uveitis have been superseded by infliximab. The 2018 EULAR Recommendations for BD indicate infliximab as a first-choice treatment for ophthalmitis although there is concern regarding its functional decline over time. ${ }^{21}$ Adalimumab is not approved for BD uveitis because no related clinical studies were initiated at the time of development. ${ }^{22,23}$ However, some studies have reported adalimumab suppressed uveitis in $\mathrm{BD} .^{24,25}$

\section{Intestinal Type BD}

Intestinal type $\mathrm{BD}$ often forms an ulcer in the ileocecum as well as the gastrointestinal tract but rarely causes perforation. It accounts for $15-20 \%$ of all BD cases and usually requires surgery. Intestinal type BD is treated with GCs and 5-aminosalicylic acid or salazosulfasalazine according to the therapeutic guidelines for inflammatory bowel disease. However, the long-term use GC causes complications including perforation caused by a delay in wound healing. Infliximab and adalimumab are effective in patients who are resistant to GCs and 5-aminosalicylic acid or salazosulfasalazine. ${ }^{26-28}$ In addition, adalimumab and infliximab were highly effective in clinical trials of cases with a typical ulcer $1 \mathrm{~cm}$ in diameter in the ileocecum where GCs or immunosuppressants were not effective part. ${ }^{26,29}$ However, TNF inhibitor treatment is unsuccessful in approximately $20 \%$ of patients.

\section{Nervous Type BD}

Nervous type BD can be classified as an acute model/ANB (acute neurological attacks in BD) and chronic progressive/ CPNB (chronic progressive neurological BD). Both types require treatment because they reduce the quality of life for patients. Infliximab has been used in a model of nervous BD, but evidence is lacking for its use in multi-cases. Conventional treatment consisting of GCs and pulse therapy is used for the induction of remission in ANB. However, the effects of infliximab on attack prevention have only been reported for backward cohorts and cases. ${ }^{30}$ MTX generally improved convalescence in $\mathrm{CPN}^{31}$ and infliximab was effective in cases where MTX was ineffective. ${ }^{32}$

\section{Vascular Type BD}

Vascular type BD describes numerous diseases that can develop in a single patient related to lesions of the vein and artery system. Genuine and false aneurysms appear in arteries and clot formation occurs in veins. The symptoms of vascular type BD are likely to be worsened by stimulation, similar to intestinal tract type BD. In addition, in this type BD, false aneurysms occur in blood vessel anastomotic regions after aneurysms are substituted with artificial blood vessels, making it difficult to treat. The use of glucocorticoids or immunosuppressants for vascular lesions in $\mathrm{BD}$ has been recommended by EULAR, although robust evidence for their effects is lacking. ${ }^{33,34}$ Anti-TNF preparations (infliximab and adalimumab) were reported to be effective in cases resistant to glucocorticoids or immunosuppressants. ${ }^{35,36}$ AntiTNF preparations are often used in intractable cases and those requiring surgical management, such as those with intestinal tract type BD. Discontinuation studies in RA and the dosage period of biological therapeutics have been reported, but there is no clear evidence for discontinuation in BD. However, remission was maintained without uveitis for one year even when substitute treatments, such as immunosuppressants were used in cases that could not continue infliximab. ${ }^{37}$

\section{Psoriatic Arthritis (PsA)}

PsA is broadly classified as a form of vertebral pain (spondyloarthritis: SpA). There is often a "peripheral phenotype" in which patients' symptoms mainly comprise synovium inflammation similar to that in RA. However, some cases exhibit "body axis characteristics" symptoms, and these cases are difficult to identify with AS in X-ray 
views. In addition, dactylitis that shows enthesitis and swelling in all fingers and toes has various joint symptoms. Body axis-related joint symptom is stronger in inflammation of the ligament than in synovium, and hardening lesions resulting from the ossification of the ligament is the primary problem, rather than bone destruction. Body axis-related joint lesions were reported in $25-70 \%$ of cases. $^{38}$ It is important to know which cytokines are related to joint symptoms because the recommended drugs differ for peripheral joint pain, body axis-related joint pain, enthesitis, and dactylitis in PsA. ${ }^{39,40}$

It was previously reported that cyclosporine was effective for treating skin lesions in patients with psoriasis when psoriasis patient incorporated the examination to check the effectiveness of cyclosporine for RA. ${ }^{41}$ Another report suggested that $\mathrm{T}$ cell-related immunity ( $\mathrm{T}$ helper $(\mathrm{Th}) 1$ reactions) participated in the skin symptom of psoriasis patient. Then, IL-17 and IL-22 were shown to be involved in psoriasis lesions, indicating Th17 cells were also involved. ${ }^{42,43}$ IL-12 produced by dendritic cells is important for the differentiation of Th1. In addition, IL-23 produced by dendritic cells increases and maintains IL-17 cells. IL-12 and IL-23 form a heterodimer comprising a subunit of p35/p40 and p19/p40, respectively. p40 is the subunit common to IL-12 and IL-23. The expression of $\mathrm{p} 40$, but not $\mathrm{p} 35$, was increased in the skin lesions of psoriasis patients, ${ }^{44}$ and IL-17 and IL-22 (Th17related molecules) in psoriasis skin lesions were related to treatments, such as etanercept and cyclosporine. ${ }^{40,45}$ In addition, psoriasis-like exanthem and expression of IL-17A occurred when IL-23 was injected to the skin of mice. ${ }^{46}$ It is thought that Th17 cells contribute more significantly to skin lesion compared with Th1 cells. As for TNF $\alpha$, it turns out that it is involved in the condition of patients' dendritic cells, Th17, and epidermal cornification cells, both situations broadly. Although PsA exhibits various joint symptoms, the cytokines involved might vary according to the symptoms. The participation of TNF $\alpha$ is strongly suggested in peripheral arthritis, because TNF inhibitors suppressed inflammation in peripheral joint pain in RA and prevent joint destruction. However, local cells in tissues produce IL-23, IL-17 and
IL-22, which might participate in enthesitis. ${ }^{47,48}$ Previous studies reported enthesitis was IL-17A-dependent in animal models. ${ }^{47,49}$ Enthesitis might have a similar cytokine profile to skin lesions in psoriasis, because $\gamma \delta$ T cells in the human vertebral column spinous process produce IL-17A by an IL23-independent mechanism. ${ }^{50}$

The priority of biological therapeutics for the treatment of joint symptoms of PsA is shown in Table 1. TNF inhibitors have the best efficacy against peripheral joint pain. The IL$17 \mathrm{~A}$ inhibitor has a superior effect to the IL-12/23p40 inhibitor, but similar efficacy to TNF inhibitor. ${ }^{51-53}$ However, the effects of brodalumab, an IL-17 receptor A inhibitor, on preventing joint destruction are unclear. $^{54}$ In addition, guselkumab, an IL-12/23p19 inhibitor, is superior to IL-12/ 23 p40 inhibitors for the improvement of clinical joint, and has similar efficacy to TNF inhibitors and the IL-17 inhibitor. ${ }^{55}$ Although the benefit of IL-12/23p40 for peripheral joint pain is unclear, improvements in joint pain and joint destruction were significant compared with placebo in a clinical study. ${ }^{56,57}$ In addition, an IL-12/23p40 inhibitor significantly improved enthesitis compared with a TNF inhibitor, ${ }^{58}$ and had benefit for dactylitis. In addition, a high percentage of cases continue ustekinumab treatment because it has very low accumulation rate, which reduces the potential for harmful phenomena. ${ }^{58}$ TNF inhibitors and anti-IL-17 biological therapeutics are considered first choice for the treatment of axis-related joint pain. The EULAR recommendations suggest TNF inhibitors are the first choice for treatment, but IL-17A inhibitors are also recommended as first choice in some cases. ${ }^{59}$ IL-17A inhibitors were superior regarding the rapidity of effect and reducing disease severity in psoriasis exanthem, similar to TNF inhibitors. However, IL-17A inhibitors should be used with caution for inflammatory bowel disease, because IL-17A is necessary for maintenance of the enterobacterial flora.

\section{Ankylosing Spondylitis (AS)}

AS, a chronic inflammatory disease that develops at a young age, is characterized by ankylosis observed in sacroiliac joint by imaging. Furthermore, lesions occur

Table I Priority of Biological Therapeutics for the Treatment of Joint Symptoms of PsA

\begin{tabular}{|l|c|}
\hline Pattern of Arthritis & Priority of Biological Therapeutics \\
\hline Peripheral Arthritis & TNF $\alpha$ inhibitor $\approx$ IL-I7 inhibitor $\approx \mathrm{pI} 9>\mathrm{p} 40$ inhibitor \\
Axial Spondyloarthritis & TNF $\alpha$ inhibitor $\approx$ IL-I7 inhibitor $>\mathrm{p} 40$ inhibitor \\
Adhesive Inflammation & $\mathrm{P} 40$ inhibitor $\geq \mathrm{TNF} \alpha$ inhibitor $\approx$ IL- I7 inhibitor \\
Dactylitis & $\mathrm{P} 40$ inhibitor $\geq \mathrm{TNF} \alpha$ inhibitor $\approx \mathrm{IL}-\mathrm{I7}$ inhibitor \\
\hline
\end{tabular}


along the vertebral column from the upper part to the lower part, finally causing total ankylosis of the vertebral column. The classification standard (revision New York standard) comprises clinical and X-ray imaging. ${ }^{60}$ Without a specific spot that meets the criteria of "more than grade 3 on one side and more than grade 2 on both sides" in sacroiliac joint with X-rays, we cannot make a diagnostic decision. This was the classification standard in 1984 and only non-steroidal anti-inflammatory drugs (NSAID) were available, which did not alter the disease course. ${ }^{60}$ Currently, TNF inhibitors are administered, which markedly improve symptoms leading to an early cure. The Assessment of Spondyloarthritis International Society (ASAS) classified axial spondyloarthritis (axSpA) in $2009 .^{61}$ Although the main disease of this classification is AS, it includes axSpA, which is not present in the revised New York standard of AS. Actually, axSpA, which meets the x-ray standard, almost matches AS according to the revised New York standard. ${ }^{62}$ However, non-axSpA does not necessary occur in early AS. ${ }^{63,64}$ AS is characterized by negative CRP, and non-axSpA tends to have negative or low CRP values. Therefore, inflammation assessed by magnetic resonance imaging is likely to be low. ${ }^{65}$ Because the ASAS standard includes diseases other than AS, we should carefully consider the diagnosis. However, the ASAS standard is very useful for the diagnosis of AS.

TNF $\alpha$, IL-17A and IL-23 are increased in patient with AS. ${ }^{66-68}$ It is thought that TNF $\alpha$ is important at the final stage of inflammation, and many studies have reported that TNF inhibitors are effective for AS. It is thought that IL-17A participates in the maintenance of chronic inflammation related to TNF $\alpha$ receptor signaling and IL-23 participates in the differentiation and IL-17 production of Th17 cells. ${ }^{69}$ TNF inhibitors and IL-17 inhibitors are effective in AS. However, when AS was treated with TNF inhibitors, serum IL-17A levels unchanged regardless of the treatment effect. ${ }^{70,71}$ Therefore, IL-17 inhibitors might be used for patients who derive no benefit from TNF inhibitors. ${ }^{72}$ In addition, IL-17 inhibitors have similar efficacy to TNF inhibitors in active AS patients without biological therapeutics. ${ }^{73}$ These results suggest IL-17A participates uniquely in the pathophysiology of AS. Although IL-23/p19 or IL-23/p40 inhibitors did not show a statistically significant improvement, they were effective in patients with AS. ${ }^{74,75}$ From this, although PsA and As are related diseases, the role of IL23 in enthesitis is different between these diseases.
MTX has not been confirmed for sacroiliac joint and the vertebral column, the central lesions in AS and non-axSpA. Salazosulfasalazine is validated only for peripheral joints when accompanied by peripheral joint pain. ${ }^{76}$ Therefore, TNF inhibitors or IL-17 inhibitors are used when NSAIDs can be used and BASDAI score is greater than 4 . Recommendations by ACR, Spondylitis Association of America (SAA) and Spondyloarthritis Research and Treatment Network (SPARTAN) were updated in 2019. ${ }^{77}$ The first-line drug is usually a TNF inhibitor. Uveitis in the front of the eye is detected in about $1 / 3$ of AS cases. Therefore, in such cases, TNF inhibitors should be given priority. TNF and IL-17 inhibitors are highly effective when lesions are evaluated clinically by BASDAI, but their effects on suppressing bone lesion progress are unclear. This is because no system to evaluate bone lesions in AS patients has been established compared with RA and PsA patients. However, the possibility has been suggested that TNF inhibitor and IL-17 inhibitor allow for gentle and quiet long-term incorruptibility. ${ }^{78}$ In addition, one report indicated the possibility that bone deterioration was inhibited after 2 years of secukinumab treatment. ${ }^{79}$ Therefore, we anticipate the results of analyses of other examples of this treatment over longer periods. At present, it is not recommended to discontinue or reduce TNF inhibitors or IL-17 inhibitor use, even if disease activity has slowed according to evaluations such as BASDAI.

\section{Anti-Neutrophil Cytoplasmic Antibody (ANCA)-Related Arthritis}

Vasculitis syndrome is classified according to the size of affected blood vessel by the Chapel Hill Consensus Conference (CHCC) classification (CHCC, 2012). ${ }^{80}$ The classification of small vasculitis in CHCC 2012 are an immune complex type and an ANCA-related vasculitis type. The former type comprises anti-glomerular basement membrane antibody disease, IgA vasculitis, and cryoglobulinemia-related vasculitis. ANCA-related vasculitis includes microscopic polyangiitis (MPA), polyangiitisrelated granulation tissue class symptom (granulomatosis with polyangiitis (GPA) or Wegener granulomatosis), and eosinophil- and polyangiitis-related granulation tissue class symptom (eosinophilic granulomatosis with polyangiitis (EGPA), Churg-Strauss syndrome, or allergic granulomatous vasculitis). ${ }^{80}$ MPA and GPA require similar therapeutic strategies although they are different diseases. 
The pathogenesis of MPA and GPA is thought to involve neutrophil extracellular traps (NETs) released from ANCAactivating neutrophil, which affect endothelial cells via inflammatory cytokines. ${ }^{81,82}$ EGPA is different from MPA and GPA because it is an eosinophil-related tissue disorder. In EGPA, Th1/17 cells participate in granuloma formation, TRh2 produce IL-4, IL-5, and IL-13, and B cells secrete IgE and ANCA. IL-5 activates eosinophil, which causes the tissue disorder. Anti-IL-5 biological therapeutics is used for the treatment of EGPA and anti-B-cell therapy is used for MPA and GPA.

Rituximab is a monoclonal antibody that recognizes CD20 expressed on the surface of B-cells. After binding to CD20, rituximab kills B-cells by antibody-dependent cellular cytotoxicity. Rituximab is covered by health insurance for the treatment of MPA and GPA in Europe and the USA. ${ }^{83-85}$ However, GCs plus rituximab is positioned as an alternative to GCs plus cyclophosphamide treatment for MPA and GPA. In MPA and GPA, rapidly progressive glomerulonephritis is often complicated as an organ disorder, and clinicians often hesitate to use GCs plus rituximab because cyclophosphamide used in standard regimen can affect liver function test outcomes. However, because there is no need for weight loss, and rituximab used in limited quantities does not cause renal failure, there are many clinical situations where its use is appropriate.

Mepolizumab, a monoclonal antibody that recognizes IL-5, is covered by health insurance for the treatment of severe bronchial asthma. This drug has a strong eosinophilic suppressive effect mediated by IL-5 inhibition and is covered by health insurance for the treatment of EGPA. ${ }^{86}$ GCs are a first-line drug for the treatment of EGPA, but not MPA and GPA, because not many cases require immunosuppression in the early stages of disease. Mepolizumab can achieve rapid drug weight loss of GCs compared with placebo and can achieve longer-term remission maintenance. ${ }^{86}$ The use of mepolizumab is considered in cases where the use of GCs or immunosuppressants is difficult because of the occurrence of side effects.

\section{Adult Still's Disease (ASD)}

ASD is not an autoimmune disease because it lacks autoreactive T-cells and autoantibodies. Its pathogenesis involves the activation of monocytes/macrophages and the production of inflammatory cytokines. Therefore, ASD is classified as a CTD-ID, but it is considered an autoinflammatory disease. ${ }^{87}$ IL-6, IL-18, and TNF $\alpha$ are present at high levels in patients with ASD, although many cytokines have been reported. ${ }^{87,88}$ The characteristics of ASD include high levels of ferritin and IL-18. In ASD, increased IL-18 is related to fever, joint pain, and skin symptoms, which are normalized by GC treatment. ${ }^{89}$ In addition, IL-6 located downstream to IL-18 might be increased or decreased in ASD. ${ }^{90}$

Regarding biological therapeutics for ASD, TNF $\alpha$, IL-1, and IL-6 inhibitors have shown benefit. A meta-analysis of clinical studies reported the IL-1 inhibitor, anakinra, improved the remission rate and GC-induced weight loss. ${ }^{91}$ In addition, another IL-1 inhibitor, canakinumab, improved juvenile idiopathic arthritis similar to ASD in a clinical trial. ${ }^{92}$ A TNF inhibitor was also effective for ASD in a forward open clinical study. ${ }^{93}$ Furthermore, Kaneko et al ${ }^{94}$ reported that tocilizumab had a high remission rate for ASD compared with placebo in a double-blind study. Based on these studies, tocilizumab was approved for ASD.

The condition of patients requiring a prescription of life convalescence of ASD includes macrophage activation syndrome (MAS). MAS defines the prognosis of ASD. Although there is no specific treatment for ASD, an adaptation of tocilizumab treatment can cause MAS. It is assumed that MAS develops in patients where "ASD that the effect is insufficient by existing treatment", which is an adaptation of tocilizumab. Therefore, it is necessary to consider MAS development after tocilizumab treatment or the use of TNF $\alpha$ or IL-1 inhibitors. ${ }^{95-97}$ However, it is reported that a clear cause-effect between the tocilizumab dosage and MAS onset could not be found from the results of analyzed cases which MAS developed after administration of tocilizumab for juvenile idiopathic arthritis resembling ASD. ${ }^{98}$ Pathology resembling cytokine storm might cause MAS. Therefore, biological therapeutics might cause changes in the cytokine cascade and trigger MAS onset. Therefore, it is necessary to consider the usefulness of tocilizumab against ASD patient developing MAS.

\section{Combination Therapy Using Biological Therapeutics}

The cost of biological therapeutics per patient with RA is approximately 100 times the costs of treatment with a combination of conventional disease-modifying antirheumatic drugs (DMARD). Graudal et $\mathrm{al}^{99}$ reported a meta-analysis of randomized trials of combination therapy with and without TNF inhibitors in RA. They concluded the RA guidelines should recommend combination treatment before the initiation of TNF inhibitors. The effect of combination therapy including biological therapeutics was also reported in patients with CTD-ID. ${ }^{100,101}$ 
AS is a chronic and inflammatory disease, and the management of this disease consists of pharmacological and nonpharmacological modalities. Until recently, pharmacological treatment options have been very limited. However, as mentioned earlier, the development of novel biological therapeutics has revolutionized the management of this disease. In addition, the usefulness of combination therapy with TNF inhibitor and NSAID and DMARD was also reported. ${ }^{102-104}$

Skin and joint manifestations associated with psoriasis and PsA can significantly impact a patient's quality of life. Successful treatment is imperative to improve the signs and symptoms of disease. For patients with moderate to severe active PsA, combination therapy with methotrexate and TNF inhibitors is considered first-line treatment. ${ }^{105}$ These new therapeutic concepts for PsA include a high efficacy of combination therapy in those unable to tolerate or who have failed TNF inhibitor treatment. ${ }^{106}$

Relapsing ocular involvement is a major manifestations of BD and occurs in $60-80 \%$ of patients, resulting in retinal vasculitis, neuropathy or panuveitis. ${ }^{107}$ TNF inhibitors are effective and safe in these patients, especially regarding its corticosteroid- and immunosuppressive drug-sparing effects. ${ }^{108}$

\section{New Therapeutic Concept}

Biological therapeutics are more expensive compared with small molecule drugs, such as JAK inhibitors. Drug costs are more likely to be reduced if generics, such as JAK inhibitors are available. ${ }^{109-111}$ Depending on the disease, this approach is likely to become more mainstream. However, autoimmune or self-inflammatory disease have an abnormal cytokine production indicating the potential benefit of biological therapeutics. The recent marketed recycling antibodies are the preparation which was developed so that antibody preparation binds to the antigen repeatedly in vivo. ${ }^{112}$ It is thought that even if it leads to such a technique reducing the dosage number of times of biological therapeutics, it becomes useful in economic aspect.

\section{Conclusions}

Cytokines, such as IL-6, have pleiotropic effects and promote various effects in numerous cell types. Cytokines also have overlapping and sometimes redundant effects. Therefore, even if the effects of a specific cytokine are completely blocked, similar effects can be mediated by another cytokine. This might explain why some cases treated with biological therapeutics show no beneficial effect and the blocking a specific cytokine does not always cause serious side effect.
When disease activity is controlled by biological therapeutics, autoimmune diseases can sometimes occur. For example, psoriasis exanthema develops during treatment for $\mathrm{RA}$ or $\mathrm{BD}$, a phenomenon termed paradoxical reaction, which is thought to be caused by the overlapping functions of cytokines. When the activity of a disease is inhibited by blocking a specific cytokine, levels of another cytokine are thought to be increased in vivo leading to the induction of autoimmune disease. An example is the onset of MAS by tocilizumab treatment for ASD.

The biological therapeutics contributes to greatly improving convalescence around RA. Other CTD are also experiencing the calming of the disease activity by the development of new biological therapeutics and adaptation expansion of such drugs. In this review, we addressed the current situation of biological therapeutics for CTD-ID including Behcet's disease, psoriatic arthritis, ankylosing spondylitis, anti-neutrophil cytoplasmic antibody-related arthritis, and adult Still's disease, as well as the choice of biological therapeutics in the clinical practice. Further developing biological therapeutics is expected in the scleroderma and the inflammation of muscle-related disease that there remained it.

\section{Acknowledgments}

This review was supported in part by grants (15K08657 and 19K07948 to S.N.) from the Ministry of Education, Culture, Science and Technology of Japan. We thank Edanz (https://jp.edanz.com/ac) for editing a draft of this manuscript.

\section{Disclosure}

The authors declare no conflicts of interests regarding the publication of this article.

\section{References}

1. Klemperer P, Pollack AD, Baehr G. Diffuse collagen disease: acute disseminated lupus erythematosus and diffuse scleroderma. JAMA. 1942;119(4):331-332. doi:10.1001/jama.1942.02830210023006

2. Mosca M, Tani C, Vagnani S, et al. The diagnosis and classification of undifferentiated connective tissue diseases. J Autoimmun. 2014;4849:50-52. doi:10.1016/j.jaut.2014.01.019

3. Fernandez AP. Connective tissue disease: current concepts. Dermatol Clin. 2019;37(1):37-48. doi:10.1016/j.det.2018.07.006

4. Kunkel HG, Tan EM. Autoantibodies and disease. Adv Immunol. 1964;27:351-395. doi:10.1016/s00658-2776(08)60711-7

5. Sharp GC, Irvin WS, Tan EM, et al. Mixed connective tissue disease an apparently distinct rheumatic disease syndrome associated with a specific antibody to an extractable nuclear antigen (ENA). $\mathrm{Am}$ $J$ Med. 1972;52(2):148-159. doi:10.1016/0002-9343(72)90064-2 
6. Stefanski AL, Tomiak C, Pleyer U, et al. The diagnosis and treatment of Sjogren's syndrome. Dtsch Arztebl Int. 2017;114 (20):354-361. doi:10.3238/arztebl.2017.0354

7. Gerfaud-Valentin M, Jamilloux Y, Iwaz J, Seve P. Adult-onset Still's disease. Autoimmun Rev. 2014;13(7):708-722. doi:10.1016/j.autrev.2014.01.058

8. Kanakis MA, Vaiopoulos AG, Vaiopoulos GA, Kaklamanis PG. Epididymo-Orchitis in Bechet's disease: a review of the wide spectrum of the disease. Acta Med Iran. 2017;55(8):482-485.

9. Chaturvedi S, McCrae KR. Diagnosis and management of the antiphospholipid syndrome. Blood Rev. 2017;31(6):406-417. doi:10.1016/S0140-6736(13)60594-2

10. Roy A, Nair S, Sen N, et al. In silico methods for design of biological therapeutics. Methods. 2017;131:33-65. doi:10.1016/j. ymeth.2017.09.008

11. Weiner G. Rituximab: mechanism of action. Semin Hematol. 2010;47(2):115-123. doi:10.1053/j.seminhematol.2010.01.011

12. Smolen JS, Han C, Bala M, et al. Evidence of radiographic benefit of treatment with infliximab plus methotrexate in rheumatoid arthritis patients who had no clinical improvement: a detailed subanalysis of data from the anti-tumor necrosis factor trial in rheumatoid arthritis with concomitant therapy study. Arthritis Rheum. 2005;52:1020-1030. doi:10.1002/art.20982

13. Greco A, De Virgillo A, Ralli M, et al. Behcet's disease: new insight into pathophysiology, clinical features and treatment options. Autoimmun Rev. 2018;17(6):567-575. doi:10.1016/j. autrev.2017.12.006

14. Ogdie A, Coates LC, Gladman DD. Treatment guidelines in psoriatic arthritis. Rheumatology (Oxford). 2020;59(suppl 1): i37-i46. doi:10.1093/rheumatology/kez383

15. Blair HA. Secukinumab: a review in ankylosing spondylitis. Drugs. 2019;79(4):433-443. doi:10.1007/s40265-019-01075-3

16. Tanaka Y. State-of-the-art treatment of systemic lupus erythematosus. Int J Rheum Dis. 2020;23(4):465-471. doi:10.1111/1756-185X.13817

17. Abbasi M, Mousavi MJ, Jamalzehi S, et al. Strategies toward rheumatoid arthritis therapy; the old and the new. $J$ Cell Physiol. 2019;234(7):10018-10031. doi:10.1002/jcp.27860

18. Mendoza-Pinto C, Garcia-Carrasco M, Jimenez-Hernandez M, et al. Etiopathogenesis of Behcet's disease. Autoimmun Rev. 2010;9(4):241-245. doi:10.1016/j.autrev.2009.10.005

19. Mege JL, Dilsen N, Sanguedolce V, et al. Overproduction of monocyte derived tumor necrosis factor alpha, interleukin (IL) 6 , IL-8 and increased neutrophil superoxide generation in Behçet's disease. A comparative study with familial Mediterranean fever and healthy subjects. $J$ Rheumatol. 1993;20:1544-1549.

20. Hirohata S, Kikuchi H. Behçet's disease. Arthritis Res Ther. 2003;5:139-146. doi:10.1186/ar757

21. Hatemi G, Christensen R, Bang D, et al. 2018 update of the EULAR recommendations for the management of Behçet's syndrome. Ann Rheum Dis. 2018;77:808-818. doi:10.1136/ annrheumdid-2018-213225

22. Jaffe GJ, Dick AD, Brézin AP, et al. Adalimumab in patients with active noninfectious uveitis. $N$ Engl J Med. 2016;375:932-943. doi:10.1056/NEJMoa1509852

23. Nguyen QD, Merrill PT, Jaffe GJ, et al. Adalimumab for prevention of uveitic flare in patients with inactive non-infectious uveitis controlled by corticosteroids (VISUAL II): a multicentre, double-masked, randomised, placebo-controlled phase 3 trial. Lancet. 2016;388:1183-1192. doi:10.1016/S0140-6736(16)31339-3

24. Interlandi E, Leccese P, Olivieri I, et al. Adalimumab for treatment of severe Behçet's uveitis: a retrospective long-term followup study. Clin Exp Rheumatol. 2014;32:S58-S62.

25. Fabiani C, Vitale A, Emmi G, et al. Efficacy and safety of adalimumab in Behçet's disease-related uveitis: a multicenter retrospective observational study. Clin Rheumatol. 2017;36:183-189. doi:10.1007/s10067-016-3480-x
26. Tanida S, Inoue N, Kobayashi K, et al. Adalimumab for the treatment of Japanese patients with intestinal Behçet's disease. Clin Gastroenterol Hepatol. 2015;13:940-948. doi:10.1016/j. cgh.2014.08.042

27. Hibi T, Hirohata S, Kikuchi H, et al. Infliximab therapy for intestinal, neurological, and vascular involvement in Behcet disease: efficacy, safety, and pharmacokinetics in a multicenter, prospective, open-label, single-arm phase 3 study. Medicine (Baltimore). 2016;95:e3863. doi:10.1097/MD.0000000000003863

28. Vallet H, Riviere S, Sanna A, et al. Efficacy of anti-TNF alpha in severe and/or refractory Behçet's disease: multicenter study of 124 patients. J Autoimmun. 2015;62:67-74. doi:10.1016/j. jaut.2015.06.005

29. Kinoshita H, Kunisaki R, Yamamoto H, et al. Efficacy of infliximab in patients with intestinal Behçet's disease refractory to conventional medication. Intern Med. 2013;52:1855-1862. doi:10.2169/internlmedicine.52.0589

30. Fujikawa K, Aratake K, Kawakami A, et al. Successful treatment of refractory neuro-Behcet's disease with infliximab: a case report to show its efficacy by magnetic resonance imaging, transcranial magnetic stimulation and cytokine profile. Ann Rheum Dis. 2007;66:136-137. doi:10.1136/ard.2006.056804

31. Hirohata S, Kikuchi H, Sawada T, et al. Retrospective analysis of long-term outcome of chronic progressive neurological manifestations in Behcet's disease. J Neurol Sci. 2015;349:143-148. doi:10.1016/j.jns.2015.01.005

32. Kikuchi H, Aramaki K, Hirohata S. Effect of infliximab in progressive neuro-Behçet's syndrome. $J$ Neurol Sci. 2008;272:99-105. doi:10.1016/j.jns.2008.05.002

33. Ntatsaki E, Mooney J, Scott DG, et al. Systemic rheumatoid vasculitis in the era of modern immunosuppressive therapy. Rheumatology (Oxford). 2014;53:145-152. doi:10.1093/rheumatology/ket326

34. Turesson C, Schaid DJ, Weyand CM, et al. Association of HLA-C3 and smoking with vasculitis in patients with rheumatoid arthritis. Arthritis Rheum. 2006;54:2776-2783. doi:10.1002/art.22057

35. Adler S, Baumgartner I, Villiger PM. Behçet's disease: successful treatment with infliximab in 7 patients with severe vascular manifestations. A retrospective analysis. Arthritis Care Res (Hoboken). 2012;64:607-611. doi:10.1002/acr.21557

36. Aamar S, Peleg H, Leibowitz D, et al. Efficacy of adalimumab therapy for life-threatening pulmonary vasculitis in Behçet's disease. Rheumatol Int. 2014;34:857-860. doi:10.1007/s00296-0132693-4

37. Kawaguchi T, Kawazoe Y, Kamoi K, et al. Clinical course of patients with Behçet's uveitis following discontinuation of infliximab therapy. Jpn J Ophthalmol. 2014;58:75-80. doi:10.1007/ s10384-013-0283-3

38. Feld J, Chandran V, Haroon N, et al. Axial disease in psoriatic arthritis and ankylosing spondylitis: a critical comparison. Nat Rev Rheumatol. 2018;14:363-371. doi:10.1038/s41584-018-0006-8

39. Coates LC, Kavanaugh A, Mease PJ, et al. Group for research and assessment of psoriasis and psoriatic arthritis 2015 treatment recommendations for psoriatic arthritis. Arthritis Rheumatol. 2016;68:1060-1071. doi:10.1002/art.39573

40. Gossec L, Smolen JS, Ramiro S, et al. European League Against Rheumatism (EULAR) recommendations for the management of psoriatic arthritis with pharmacological therapies: 2015 update. Ann Rheum Dis. 2016;75:499-510. doi:10.1136/annrheumdis2015-208337

41. Mueller W, Herrmann B. Cyclosporin A for psoriasis. $N$ Engl J Med. 1979;301:555. doi:10.1056/NEJM197909063011016

42. Guttman-Yassky E, Lowes MA, Fuentes-Duculan J, et al. Low expression of the IL-23/Th17 pathway in atopic dermatitis compared to psoriasis. J Immunol. 2008;181:7420-7427. doi:10.4049/ jimmunol.181.10.7420 
43. Harper EG, Guo C, Rizzo H, et al. Th17 cytokines stimulate CCL20 expression in keratinocytes in vitro and in vivo: implications for psoriasis pathogenesis. $J$ Invest Dermatol. 2009;129:2175-2183. doi:10.1038/jid.2009.65

44. Lee E, Trepicchio WL, Oestreicher JL, et al. Increased expression of interleukin 23 p19 and p40 in lesional skin of patients with psoriasis vulgaris. $J$ Exp Med. 2004;199:125-130. doi:10.1084/ jem. 20030451

45. Haider AS, Lowes MA, Suárez-Fariñas M, et al. Identification of cellular pathways of "type 1," Th17 T cells, and TNF- and inducible nitric oxide synthase-producing dendritic cells in autoimmune inflammation through pharmacogenomic study of cyclosporine A in psoriasis. J Immunol. 2008;180:1913-1920. doi:10.4049/jimmunol.180.3.1913

46. Zheng Y, Danilenko DM, Valdez P, et al. Interleukin-22, a $\mathrm{T}(\mathrm{H}) 17$ cytokine, mediates IL-23-induced dermal inflammation and acanthosis. Nature. 2007;445:648-651. doi:10.1038/nature05505

47. Sherlock JP, Joyce-Shaikh B, Turner SP, et al. IL-23 induces spondyloarthropathy by acting on ROR- $\gamma \mathrm{t}+\mathrm{CD} 3+\mathrm{CD} 4-\mathrm{CD} 8-$ entheseal resident $\mathrm{T}$ cells. Nat Med. 2012;18:1069-1076. doi: $10.1038 / \mathrm{nm} .2817$

48. Ahlfors H, Morrison PJ, Duarte JH, et al. IL-22 fate reporter reveals origin and control of IL-22 production in homeostasis and infection. J Immunol. 2014;193:4602-4613. doi:10.4049/ jimmunol.1401244

49. Benham H, Rehaume LM, Hasnain SZ, et al. Interleukin-23 mediates the intestinal response to microbial $\beta$-1,3-glucan and the development of spondyloarthritis pathology in SKG mice. Arthritis Rheumatol. 2014;66:1755-1767. doi:10.1002/art.38638

50. Cuthbert RJ, Watad A, Fragkakis EM, et al. Evidence that tissue resident human enthesis $\gamma \delta$ T-cells can produce IL-17A independently of IL-23R transcript expression. Ann Rheum Dis. 2019;78:1559-1565. doi:10.1136/annrheumdis-2019-215210

51. Mease P, van der Heijde D, Landewé R, et al. Secukinumab improves active psoriatic arthritis symptoms and inhibits radiographic progression: primary results from the randomised, double-blind, phase III FUTURE 5 study. Ann Rheum Dis. 2018;77:890-897. doi:10.1136/annrheumdis-2017-212687

52. Mease PJ, van der Heijde D, Ritchlin CT, et al.; SPIRIT-P1 Study Group. Ixekizumab, an interleukin-17A specific monoclonal antibody, for the treatment of biologic-naive patients with active psoriatic arthritis: results from the 24-week randomised, double-blind, placebo-controlled and active (adalimumab)-controlled period of the phase III trial SPIRIT-P1. Ann Rheum Dis. 2017;76:79-87. doi:10.1136/annrheumdis-2016-209709

53. van der Heijde D, Gladman DD, Kishimoto M, et al. Efficacy and safety of ixekizumab in patients with active psoriatic arthritis: 52-week results from a phase III study (SPIRIT-P1). J Rheumatol. 2018;45:367-377. doi:10.3899/jrheum.170429

54. Mease PJ, Genovese MC, Greenwald MW, et al. Brodalumab, an anti-IL17RA monoclonal antibody, in psoriatic arthritis. $N$ Engl $J$ Med. 2014;370:2295-2306. doi:10.1056/NEJMoa1315231

55. Deodhar A, Gottlieb AB, Boehncke WH, et al.; CNTO1959PSA2001 Study Group. Efficacy and safety of guselkumab in patients with active psoriatic arthritis: a randomised, double-blind, placebo-controlled, phase 2 study. Lancet. 2018;391:2213-2224. doi:10.1016/S0140-6736(18)30952-8

56. McInnes IB, Kavanaugh A, Gottlieb AB, et al.; PSUMMIT 1 Study Group. Efficacy and safety of ustekinumab in patients with active psoriatic arthritis: 1 year results of the phase 3, multicentre, double-blind, placebo-controlled PSUMMIT 1 trial. Lancet. 2013;382:780-789. doi:10.1016/S0140-6736(13)60594-2
57. Kavanaugh A, Ritchlin C, Rahman P, et al.; PSUMMIT-1 and 2 Study Groups. Ustekinumab, an anti-IL-12/23 p40 monoclonal antibody, inhibits radiographic progression in patients with active psoriatic arthritis: results of an integrated analysis of radiographic data from the phase 3, multicentre, randomised, double-blind, placebo-controlled PSUMMIT-1 and PSUMMIT-2 trials. Ann Rheum Dis. 2014;73:1000-1006. doi:10.1136/annrheumdis2013-204741

58. Araujo EG, Englbrecht M, Hoepken S, et al. Effects of ustekinumab versus tumor necrosis factor inhibition on enthesitis: results from the enthesial clearance in psoriatic arthritis (ECLIPSA) study. Semin Arthritis Rheum. 2019;48:632-637. doi:10.1016/j. semarthrit.2018.05.011

59. Kerschbaumer A, Smolen JS, Dougados M, et al. Pharmacological treatment of psoriatic arthritis: a systematic literature research for the 2019 update of the EULAR recommendations for the management of psoriatic arthritis. Ann Rheum Dis. 2020;79:778-786. doi:10.1136/annrheumdis-2020-217163

60. van der Linden S, Valkenburg HA, Cats A. Evaluation of diagnostic criteria for ankylosing spondylitis. A proposal for modification of the New York criteria. Arthritis Rheum. 1984;27:361-368. doi:10.1002/art.1780270401

61. Rudwaleit M, van der Heijde D, Landewé R, et al. The development of Assessment of SpondyloArthritis international Society classification criteria for axial spondyloarthritis (part II): validation and final selection. Ann Rheum Dis. 2009;68:777-783. doi:10.1136/ard.2009.108233

62. Boel A, Molto A, van der Heijde D, et al. Do patients with axial spondyloarthritis with radiographic sacroiliitis fulfil both the modified New York criteria and the ASAS axial spondyloarthritis criteria? Results from eight cohorts. Ann Rheum Dis. 2019;78:1545-1549. doi:10.1136/annrheumdis-2019-215707

63. Wang R, Gabriel SE, Ward MM. Progression of nonradiographic axial spondyloarthritis to ankylosing spondylitis: a population-based cohort study. Arthritis Rheumatol. 2016;68:1415-1421. doi:10.1002/art.39542

64. Dougados M, Sepriano A, Molto A, et al. Sacroiliac radiographic progression in recent onset axial spondyloarthritis: the 5-year data of the DESIR cohort. Ann Rheum Dis. 2017;76:1823-1828. doi:10.1136/annrheumdis-2017-211596

65. Braun A, Saracbasi E, Grifka J, et al. Identifying patients with axial spondyloarthritis in primary care: how useful are items indicative of inflammatory back pain? Ann Rheum Dis. 2011;70:1782-1787. doi:10.1136/ard.2011.151167

66. Sieper J, Braun J, Dougados M, et al. Axial spondyloarthritis. Nat Rev Dis Primers. 2015;1:15013. doi:10.1038/nrdp.2015.13

67. van Tubergen A. The changing clinical picture and epidemiology of spondyloarthritis. Nat Rev Rheumatol. 2015;11:110. doi:10.1038/nrrheum.2014.181

68. Khan MA. HLA-B27 and its subtypes in world populations. Curr Opin Rheumatol. 1995;7:263-269. doi:10.1097/00002281199507000-00001

69. Korn T, Bettelli E, Oukka M, Kuchroo VK. IL-17 and Th17 cells. Апnи Rev Immunol. 2009;27:485. doi:10.1146/annurev. immunol.021908.132710

70. Mei Y, Pan F, Gao J, et al. Increased serum IL-17 and IL-23 in the patient with ankylosing spondylitis. Clin Rheumatol. 2011;30:269-273. doi:10.1007/s10067-010-1647-4

71. Milanez FM, Saad CG, Viana VT, et al. IL-23/Th17 axis is not influenced by TNF-blocking agents in ankylosing spondylitis patients. Arthritis Res Ther. 2016;18:52. doi:10.1186/s13075-0160949-6 
72. Sieper J, Deodhar A, Marzo-Ortega H, et al.; MEASURE 2 Study Group. Secukinumab efficacy in anti-TNF-naive and anti-TNFexperienced subjects with active ankylosing spondylitis: results from the MEASURE 2 study. Ann Rheum Dis. 2017;76:571-592. doi:10.1136/annrheumdis-2016-210023

73. van der Heijde D, Cheng-Chung Wei J, Dougados M, et al.; COAST-V study group. Ixekizumab, an interleukin-17A antagonist in the treatment of ankylosing spondylitis or radiographic axial spondyloarthritis in patients previously untreated with biological disease-modifying anti-rheumatic drugs (COAST-V): 16 week results of a phase 3 randomised, double-blind, active-controlled and placebo-controlled trial. Lancet. 2018;392:2441-2451. doi:10.1016/S0140-6736(18)31946-9

74. Sieper J, Poddubnyy D, Miossec P. The IL-23-IL-17 pathway as a therapeutic target in axial spondyloarthritis. Nat Rev Rheumatol. 2019;15:747-757. doi:10.1038/s41584-019-0294-7

75. Baeten D, Østergaard M, Wei JC, et al. Risankizumab, an IL-23 inhibitor, for ankylosing spondylitis: results of a randomised, double-blind, placebo-controlled, proof-of-concept, dose-finding phase 2 study. Ann Rheum Dis. 2018;77:1295-1302. doi:10.1136/ annrheumdis-2018-213328

76. Clegg DO, Reda DJ, Abdellatif M. Comparison of sulfasalazine and placebo for the treatment of axial and peripheral articular manifestations of the seronegative spondylarthropathies: a Department of Veterans Affairs cooperative study. Arthritis Rheum. 1999;42:2325-2329. doi:10.1002/1529-0131(199911) 42:11<2325::AID-ANR10>3.0.CO;2-C

77. Ward MM, Deodhar A, Gensler LS, et al. 2019 update of the American College of Rheumatology/Spondylitis Association of America/Spondyloarthritis Research and Treatment Network Recommendations for the treatment of ankylosing spondylitis and nonradiographic axial spondyloarthritis. Arthritis Rheumatol. 2019;71:1599-1613. doi:10.1002/art.41042

78. Haroon N, Inman RD, Learch TJ, et al. The impact of tumor necrosis factor $\alpha$ inhibitors on radiographic progression in ankylosing spondylitis. Arthritis Rheum. 2013;65:2645-2654. doi:10.1002/art.38070

79. Braun J, Baraliakos X, Deodhar A, et al.; MEASURE 1 study group. Effect of secukinumab on clinical and radiographic outcomes in ankylosing spondylitis: 2-year results from the randomised phase III MEASURE 1 study. Ann Rheum Dis. 2017;76:1070-1077. doi:10.1136/annrheumdis-2016-209730

80. Jennette JC, Falk RJ, Bacon PA, et al. 2012 revised international chapel hill consensus conference nomenclature of vasculitides. Arthritis Rheum. 2013;65:1-11. doi:10.1002/art.37715

81. Gross WL, Schmitt WH, Csernok E. ANCA and associated diseases: immunodiagnostic and pathogenetic aspects. Clin Exp Immunol. 1993;91:1-12. doi:10.1111/j.1365-2249.1993.tb03345.x

82. Nakazawa D, Tomaru U, Suzuki A, et al. Abnormal conformation and impaired degradation of propylthiouracil-induced neutrophil extracellular traps: implications of disordered neutrophil extracellular traps in a rat model of myeloperoxidase antineutrophil cytoplasmic antibody-associated vasculitis. Arthritis Rheum. 2012;64:3779-3787. doi:10.1016/j.ymeth.2017.09.008

83. Stone JH, Merkel PA, Spiera R, et al.; RAVE-ITN Research Group. Rituximab versus cyclophosphamide for ANCA-associated vasculitis. N Engl J Med. 2010;363:221-232. doi:10.1002/acr.22618

84. Specks U, Merkel PA, Seo P, et al.; RAVE-ITN Research Group. Efficacy of remission-induction regimens for ANCA-associated vasculitis. $N$ Engl J Med. 2013;369:417-427. doi:10.1056/ NEJMoa1213277

85. Jones RB, Tervaert JW, Hauser T, et al.; European Vasculitis Study Group. Rituximab versus cyclophosphamide in ANCA-associated renal vasculitis. $N$ Engl $J$ Med. 2010;363:211-222. doi:10.1111/1755-5922.12280
86. Wechsler ME, Akuthota P, Jayne D, et al.; EGPA Mepolizumab Study Team. Mepolizumab or placebo for eosinophilic granulomatosis with polyangiitis. $N$ Engl J Med. 2017;376:1921-1932. doi: $10.5414 / \mathrm{CN} 110063$

87. Scheinberg MA, Chapira E, Fernandes ML, et al. Interleukin 6: a possible marker of disease activity in adult onset Still's disease. Clin Exp Rheumatol. 1996;14:653-655.

88. Fujii T, Nojima T, Yasuoka H, et al. Cytokine and immunogenetic profiles in Japanese patients with adult Still's disease. Association with chronic articular disease. Rheumatology (Oxford). 2001;40:1398-1404. doi:10.1093/rheumatology/40.12.1398

89. Kawashima M, Yamamura M, Taniai M, et al. Levels of interleukin-18 and its binding inhibitors in the blood circulation of patients with adult-onset Still's disease. Arthritis Rheum. 2001;44:550-560. doi:10.1136/ard.2009.108233

90. Jamilloux Y, Gerfaud-Valentin M, Martinon F, et al. Pathogenesis of adult-onset Still's disease: new insights from the juvenile counterpart. Immunol Res. 2015;61:53-62. doi:10.1007/s12026-014-8561-9

91. Hong D, Yang Z, Han S, et al. Interleukin 1 inhibition with anakinra in adult-onset Still disease: a meta-analysis of its efficacy and safety. Drug Des Devel Ther. 2014;8:2345-2357. doi:10.2147/DDDT.S73428

92. Ruperto N, Brunner HI, Quartier P, et al.; PRINTO; PRCSG. Two randomized trials of canakinumab in systemic juvenile idiopathic arthritis. $N$ Engl J Med. 2012;367:2396-2406. doi:10.1056/ NEJMoa1205099

93. Husni ME, Maier AL, Mease PJ, et al. Etanercept in the treatment of adult patients with Still's disease. Arthritis Rheum. 2002;46:1171-1176.

94. Kaneko Y, Kameda H, Ikeda K, et al. Tocilizumab in patients with adult-onset still's disease refractory to glucocorticoid treatment: a randomised, double-blind, placebo-controlled phase III trial. Ann Rheum Dis. 2018;77:1720-1729. doi:10.1136/ annrheumdis-2018-213920

95. Tsuchida Y, Sumitomo S, Shoda H, et al. Macrophage activation syndrome associated with tocilizumab treatment in adult-onset Still's disease. Mod Rheumatol. 2017;27:556-557. doi:10.1002/ 1529-0131(199911)42:11<2325::AID-ANR10>3.0.CO;2-C

96. Kobayashi M, Takahashi Y, Yamashita H, et al. Benefit and a possible risk of tocilizumab therapy for adult-onset Still's disease accompanied by macrophage-activation syndrome. Mod Rheumatol. 2011;21:92-96. doi:10.3109/s10165-010-0348-9

97. Souabni L, Dridi L, Ben Abdelghani K, et al. Possible macrophage activation syndrome following initiation of adalimumab in a patient with adult-onset Still's disease. Pan Afr Med J. 2014;17:94-96. doi:10.1136/annrheumdis-2016-209730

98. Yokota S, Itoh Y, Morio T, et al. Macrophage activation syndrome in patients with systemic juvenile idiopathic arthritis under treatment with tocilizumab. $J$ Rheumatol. 2015;42:712-722. doi:10.1111/j.1365-2249.1993.tb03345.x

99. Graudal N, Hubeck-Graudal T, Faurschou M, et al. Combination therapy with without tumor necrosis factor inhibitors in rheumatoid arthritis: a meta-analysis of randomized trials. Arthritis Care Res. 2015;67(11):1487-1495. doi:10.1002/acr.22618

100. Guiilevin L, Pagnoux C. Treatment of ANCA-associated vascularitides. Presse Med. 2007;36(5 Pt 2):922-927. doi:10.1016/j.lpm.2007.01.029

101. Park KY, Heo TH. Critical role of TNF inhibition in combination therapy for elderly mice with atherosclerosis. Cardiovasc Ther. 2017;35(6):e12280. doi:10.1111/1755-5922.12280

102. Sari I, Ozturk MA, Akkoc N. Treatment of ankylosing spondylitis. Turk J Med Sci. 2015;45(2):416-430. doi:10.3906/sag-1401-79

103. Sieper J, Poddubnyy D. New evidence on the management of spondyloarthritis. Nat Rev Rheumatol. 2016;12(5):282-295. doi:10.1038/nrrheum.2016.42 
104. Wu Y, Guo Y, Wang N, et al. Influence of therapeutic drugs on different manifestations of renal involvement in 907 Chinese patients with ankylosing spondylitis. Clin Nephrol. 2020;93 (6):283-293. doi:10.5414/CN110063

105. Papoutsaki M, Costanzo A. Treatment of psoriasis and psoriatic arthritis. BioDrugs. 2013;27(S1):3-12. doi:10.1007/BF03325637

106. Huynh D, Kavanaugh A. Psoriatic arthritis: current therapy and future directions. Expert Opin Pharmacother. 2013;14 (13):1755-1764. doi:10.1517/14656566.2013.810208

107. Krause L. Adamantiades-Behcet's disease. Ophthalmologe. 2005;102(4):329-334. doi:10.1007/s00347-004-1166-2

108. Hu YC, Yang YH, Lin YT, et al. Clinical manifestations and antiTNF alpha therapy of juvenile Behcet's disease in Taiwan. BMC Pediatr. 2019;19(1):232. doi:10.1186/s12887-019-1613-5

109. Berekmeri A, Mahmood F, Wittmann M, et al. Tofacitinib for the treatment of psoriasis and psoriatic arthritis. Expert Rev Clin Immunol. 2018;14(9):719-730. doi:10.1080/1744666X.2018.1512404
110. van der Heijde D, Baraliakos X, Gensler LS, et al. Efficacy and safety of filgotinib, a selective Janus kinase 1 inhibitor, in patients with active ankylosing spondylitis (TORTUGA): results from a randomized. Placebo-controlled, phase 2 trial. Lancet. 2018;392 (10162):2378-2387. doi:10.1016/S0140-6736(18)32463-2

111. Hu Q, Wang M, Jia J, et al. Tofacitinib in refractory adult-onset Still's disease: 14 cases from a single centre in China. Ann Rheum Dis. 2020;79(6):842-844. doi:10.1136/annrheumdis2019-216699

112. Fukuzawa T, Nezu J. SKY59, a novel recycling antibody for complement-mediated diseases. Curr Med Chem. 2020;27 (25):4157-4164. doi:10.2174/0929867326666191016115853

\section{Publish your work in this journal}

Open Access Rheumatology Research and Reviews is an international, peer-reviewed, open access journal publishing original research, reports, editorials, reviews and commentaries on all aspects of clinical and experimental rheumatology in the clinic and laboratory including the following topics: Pathology, pathophysiology of rheumatological diseases; Investigation, treatment and management of rheumatological diseases; Clinical trials and novel pharmacological approaches for the treatment of rheumatological disorders. The manuscript management system is completely online and includes a very quick and fair peer-review system, which is all easy to use. Visit http://www.dovepress.com/testimonials.php to read real quotes from published authors. 